\title{
Strain, disinfectant, concentration, and contact time quantitatively impact disinfectant efficacy
}

\author{
Alyssa M. West', Peter J. Teska², Caitlinn B. Lineback and Haley F. Oliver ${ }^{1 *}$
}

\begin{abstract}
Background: Transmission of healthcare-associated infections caused by antibiotic- and multi-drug resistant (MDR) pathogens (e.g. Methicillin-resistant Staphylococcus aureus (MRSA), Pseudomonas aeruginosa) are a major concern in patient care facilities. Disinfectant usage is critical to control and prevent pathogen transmission, yet the relationships among strain, disinfectant type, contact time, and concentration are not well-characterized. We hypothesized that there would be significant differences in disinfectant efficacy among clinically relevant strains under off-label disinfectant conditions, but there would be less no differences among at registered label use concentrations and contact times. The purpose of this study was to quantify the effect of disinfectant concentration and contact time on the bactericidal efficacy of clinically relevant strains of S. aureus and P. aeruginosa.

Methods: Accelerated hydrogen peroxide (AHP), quaternary ammonium compounds (Quat), and sodium hypochlorite were tested at label and reduced contact times and concentrations against four MDR P. aeruginosa strains and four MRSA strains. Quantitative EPA method MB-25-02 was used to measure disinfectant efficacy reported as $\log _{10}$ reduction.

Results: Both off-label disinfectant concentrations and contact times significantly affected efficacy of all disinfectants tested. Bactericidal efficacy varied among MRSA and $P$. aeruginosa strains.

Conclusions: The quantitative disinfectant efficacy method used highlights the inter-strain variability that exists within a bacterial species. It also underscores the need for a disinfectant validation method that takes these variances into account.
\end{abstract}

Keywords: Disinfectant, Label, Concentration, MRSA, Pseudomonas

\section{Background}

An estimated 722,000 healthcare-associated infections (HAIs) resulted in $\sim 75,000$ deaths in the United States in 2011 [1]. Methicillin-resistant Staphylococcus aureus (MRSA) is a multi-drug resistant (MDR) pathogen that caused an estimated 55,000 healthcare-associated invasive infections in the United States in 2014 [2]. Pseudomonas aeruginosa is a leading cause of hospital-acquired pneumonia and the number one cause of wound infections in burn unit patients [3]. The emergence of multidrug and antibiotic- resistant bacteria has led to an

\footnotetext{
* Correspondence: hfoliver@purdue.edu

${ }^{1}$ Department of Food Science, Purdue University, 745 Agriculture Mall Drive, West Lafayette, IN 47907, USA

Full list of author information is available at the end of the article
}

increased effort to improve cleaning and disinfection procedures in healthcare facilities.

Environmental contamination has been recently recognized as a contributing factor to HAIs. A study by Bhalla et al. found that healthcare workers frequently acquired nosocomial pathogens on their hands after coming into contact with environmental surfaces [4]. Another study tracked contamination of soft surfaces using tracer viruses [5]. This study showed that the tracer viruses easily spread from volunteers' hands to multiple soft surfaces around the healthcare facility [5]. Multiple studies have also shown that healthcare-associated pathogens can persist on surfaces in the environment for long periods of time [6, 7]. Therefore, proper disinfecting procedures are crucial in helping prevent the transmission of HAIs. 
The use of Environmental Protection Agency (EPA)registered disinfectant products is encouraged by both the CDC and EPA [8]. Users of EPA-registered products must abide by the specific concentration and contact times listed on the label in order for the disinfectant to achieve a five-log reduction. Some disinfectants need a full 10 min of surface contact time for the product to be effective. Such a long contact time can be hard to achieve in healthcare facilities due to the time-pressured environment [8]. Therefore, it is important to understand how off-label use of EPA-registered disinfectants may affect the efficacy of the product.

Disinfectant usage is a key part of environmental control to prevent HAI transmission in healthcare environments. However, the relationship between disinfectant efficacy and MDR pathogens has not been well-characterized by current disinfectant efficacy methodologies. The objective of this study was to examine the effect of disinfectant concentration and contact time on bactericidal efficacy against $S$. aureus and $P$. aeruginosa. We hypothesized that there would be quantifiable differences in disinfectant efficacy among clinically relevant strains under off-label disinfectant conditions, but there would not be significant differences among strains at defined label use concentrations and contact times.

\section{Methods}

Disinfectants and bacterial strains used in this study

In this study, we evaluated the disinfectant efficacy of AHP, Quat, and sodium hypochlorite disinfectants using EPA standard operating procedure MB-25-02 [9]. In this study, we used $S$. aureus ATCC CRM-6538 and P. aeruginosa ATCC 15442 as control strains, as well as four MDR $P$. aeruginosa strains (Table 1 ) and four MRSA strains (Table 2). Oxivir 1 (EPA 70627-56, Diversey Inc., Charlotte, NC) was selected to represent AHP disinfectants; it contained $0.5 \%$ hydrogen peroxide. The Quat-based disinfectant used was Virex Tb (EPA 7602724, Diversey Inc., Charlotte, NC), which contained 0. 105\% dimethyl benzyl ammonium chloride and 0.105\% dimethyl ethyl benzyl ammonium chloride. Avert (EPA 70627-75, Diversey Inc., Charlotte, NC) contained 1.2\% sodium hypochlorite. All three disinfectants were packaged at ready-to-use concentrations. The disinfectant label contact time was one minute for Oxivir 1 and three minutes for Virex TB. The disinfectant label contact time for Avert as a sporicidal agent against Clostridium difficile was four minutes, but as a bactericidal agent the label contact time was one minute; Avert was tested at both label contact times at label concentration.

Briefly, stainless steel coupons were inoculated with a soil load composed of $67.3 \%$ bacterial culture, $8.7 \%$ yeast, $19.2 \%$ mucin, and $4.8 \%$ bovine serum albumin. Each disinfectant was applied to inoculated coupons at a defined concentration and contact time; the surviving bacterial load was recovered after application of neutralizing buffer. Recovered bacteria were filtered onto 0 . $2 \mu \mathrm{m}$ pore membrane disc filters subsequently plated onto tryptic soy agar; colonies were counted after incubation at $37{ }^{\circ} \mathrm{C}$ for $24-48 \mathrm{~h}$.

\section{Bactericidal efficacy of disinfectants at label use, reduced concentrations, and reduced contact times}

To determine the effect of concentration on bactericidal efficacy, three disinfectant concentrations (50\%, 75\%, and $100 \%$ of label concentrations) with a constant contact time of one minute for Oxivir 1, three minutes for Virex $\mathrm{Tb}$, and four minutes for Avert were measured. Disinfectants were at ready-to-use concentrations and were diluted using hard water (according to EPA protocol) to reach lower concentration levels. Experiments were performed using stainless steel coupons at approximately $22{ }^{\circ} \mathrm{C}$. Each organism and concentration combination consisted of three disinfectant-treated coupons (technical replicates) and four phosphate buffered saline (PBS)-treated control coupons. The same set of controls was used when testing two disinfectants against the same organism with the same variable treatment. Each treatment was independently repeated three times for Oxivir 1 and Avert and five times for Virex Tb. A prior study by Hong et al. found that this method is more variable for Quat-based disinfectants, thus more replicates were conducted to minimize potential error [10]. Bactericidal efficacy was measured at four disinfectant contact times (30 s, $1 \mathrm{~min}, 2 \mathrm{~min}$, and $3 \mathrm{~min}$ ) at label concentration to determine the effect of varying disinfectant contact times. To determine the reduction of bacteria in every strain, time, and concentration

Table 1 Characteristics of Staphylococcus aureus strains used in study

\begin{tabular}{|c|c|c|c|c|c|}
\hline Species of Microorganism & ATCC Strain Name & PFGE Type & SCCmec Type & pvl gene & Isolation Source \\
\hline Methicillin-resistant Staphylococcus aureus & ATCC BAA-1717 & USA 300 & Type IV & Positive & $\begin{array}{l}\text { Adolescent patient } \\
\text { with severe sepsis }\end{array}$ \\
\hline Methicillin-resistant Staphylococcus aureus & ATCC BAA-1761 & USA 100 & Type II & Negative & Human Subject \\
\hline Methicillin-resistant Staphylococcus aureus & ATCC BAA-1720 & USA 200 & Type II & Negative & Hospital acquired \\
\hline Methicillin-resistant Staphylococcus aureus & ATCC BAA-1754 & USA 600 & Type IV & Negative & Human Subject \\
\hline Staphylococcus aureus & ATCC CRM-6538 & - & - & - & Human Lesion \\
\hline
\end{tabular}


Table 2 Characteristics of Pseudomonas aeruginosa strains used in study

\begin{tabular}{llll}
\hline Species of Microorganism & ATCC Strain Name & Isolation Source & Antibiotic Resistance \\
\hline Pseudomonas aeruginosa & ATCC BAA-2108 & Sputum Sample, human & AMX, AMP, CFZ, CXM, CAE, CTX, FOX, IPM, NIT, TGC, and TMP \\
Pseudomonas aeruginosa & ATCC BAA-2112 & Sputum Sample, human & AMX, AMP, CFZ, CLO, CXM, CAE, CTX, FOX, CRO, NIT, TGC, and TMP \\
Pseudomonas aeruginosa & ATCC BAA-2113 & Sputum Sample, human & AMX, AMP, CFZ, CLO, CXM, CAE, CTX, FOX, CRO, NIT, TGC, and TMP \\
Pseudomonas aeruginosa & ATCC BAA-2114 & Sputum Sample, human & AMX, AMP, TZP, CFZ, CLO, CXM, CAE, CTX, FOX, CRO, NIT, TGC, and TMP \\
Pseudomonas aeruginosa & ATCC 15442 & Animal room water bottle & - \\
\hline
\end{tabular}

permutation, the $\log 10$ bacterial count of each experimental treatment was compared to the corresponding control bacterial counts (control coupons were exposed to PBS instead of the disinfectant).

\section{Statistical analyses}

Statistical Analysis System (SAS) (version 9.4, SAS Institute Inc., Cary, NC) was used for all analyses. All data were transformed to $\log 10$ reduction values for analyses. All replicates were run independently for each disinfectant. One-way ANOVA was used to determine if, under label use conditions, bacterial strain type was significantly correlated to $\log 10$ reduction values $(\alpha=0.05)$. Tukey Honest Significant Difference (HSD) test was used to determine strain-specific differences. A generalized linear mixed model (GLMM) was used to assess the impact of off-label contact time, concentration, and their interactions for each disinfectant independently $(\alpha=0.05)$. Bacterial strain type was considered a random variable to determine the effect of contact time and concentration on disinfectant efficacy irrespective of strain type. An additional GLMM was used to determine specific differences in $\log 10$ reduction among strains exposed to each disinfectant; least squares means with Holm-Tukey adjustment for multiple comparisons were used to determine significant differences among the strains at off-label conditions $(\alpha=0.05)$.

\section{Results}

Disinfectant usage at label conditions has varied impact on bactericidal efficacy among strains

Overall, there were significant differences in disinfectant efficacy at label conditions among strains of both $P$. aeruginosa and MRSA (ANOVA with Tukey HSD; $P=0$. 0132 and $P<0.0001$ ), respectively (Fig. 1A). Virex Tb, at label conditions, was significantly less effective against MRSA ATCC BAA-1720 and BAA-1717 compared to all other MRSA strains tested $(P<0.05)$. Virex Tb was significantly more effective against $P$. aeruginosa strain ATCC BAA-2114 than the control $P$. aeruginosa strain $(\mathrm{P}<0.05)$.

There were no significant differences among MRSA strains at the bactericidal (one min) label contact time (Fig. 1B). At sporicidal label contact time (four min), there were significant differences in disinfectant efficacy among the strains (Fig. 1C). The S. aureus control strain and MRSA ATCC BAA-1720 both had significantly higher disinfectant susceptibility compared to MRSA ATCC BAA-1754 (ANOVA with Tukey HSD; $P<0.05$ ). Avert had a significantly higher disinfectant efficacy against $P$. aeruginosa ATCC BAA-2108 compared to all other $P$. aeruginosa strains at bactericidal contact time $(\mathrm{P}<0.05)$. There were no significant differences in disinfectant efficacy among the $P$. aeruginosa strains at sporicidal contact time.

There was a significant difference in disinfectant efficacy among the strains of $P$. aeruginosa (ANOVA with Tukey HSD; $P=0.023$ ) (Fig. 1D). Specifically, Oxivir 1 was more effective against $P$. aeruginosa ATCC BAA2113 than the $P$. aeruginosa control strain $(P<0.05)$. There were no significant differences in disinfectant efficacy among MRSA strains at label conditions.

\section{Reduced disinfectant concentrations have varied effects on bactericidal efficacy among strains}

Disinfectant concentration had an overall significant effect on the efficacy of Virex Tb (GLMM; $P<0.0001)$. The interaction between strain and disinfectant concentration was also significant $(\mathrm{P}<0.0001)$. Virex $\mathrm{Tb}$ was more effective against MRSA ATCC BAA-1761 than both MRSA ATCC BAA-1717 and BAA-1754 $(\mathrm{P}<0.0001)$ (Fig. 2A). Virex $\mathrm{Tb}$ was significantly more effective against $P$. aeruginosa ATCC BAA-2114 than P. aeruginosa ATCC BAA2108 (GLMM with Holm-Tukey Correction; $\mathrm{P}_{\mathrm{adj}}<0.0001$ ) , P. aeruginosa ATCC BAA-2113 ( $\left.\mathrm{P}_{\mathrm{adj}}=0.0078\right)$, and the control strain $\left(\mathrm{P}_{\mathrm{adj}}<0.0001\right)$ at varying disinfectant concentration (Fig. 2B).

Overall, disinfectant concentration significantly affected the efficacy of Avert (GLMM; $P=0.0209$ ). Specifically, concentrations less than defined label use resulted in increased recovery of bacteria. Avert was significantly more effective against the $S$. aureus control strain than MRSA ATCC BAA-1717 (GLMM with Holm-Tukey Correction; $\left.\mathrm{P}_{\mathrm{adj}}=0.0434\right)$ and MRSA ATCC BAA-1754 $\left(\mathrm{P}_{\mathrm{adj}}<0.0001\right)$ at varying disinfectant concentrations (Fig. 2C). Avert was also significantly more effective against $P$. aeruginosa ATCC BAA-2108 than the control strain $\left(\mathrm{P}_{\mathrm{adj}}=0.0029\right), P$. aeruginosa ATCC BAA-2112 $\left(\mathrm{P}_{\mathrm{adj}}\right.$ $=0.0015), P$. aeruginosa ATCC BAA-2113 $\left(\mathrm{P}_{\text {adj }}<0.0001\right)$, 

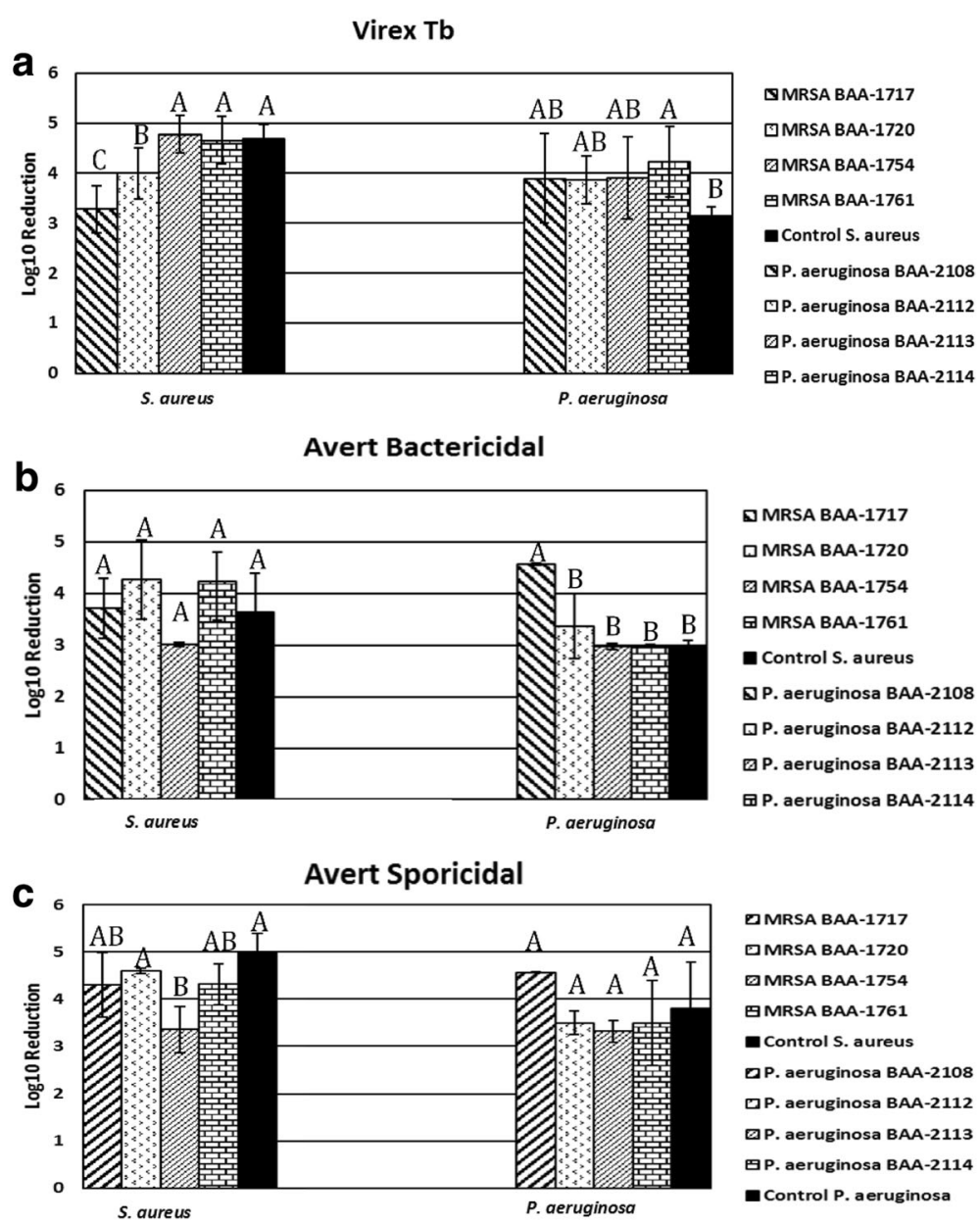

DMRSA BAA-1717

DMRSA BAA-1720

ФMRSA BAA-1754

MMRSA BAA-1761

- Control S. aureus

DP. aeruginosa BAA-2108

口P. aeruginosa BAA-2112

๑P. aeruginosa BAA-2113

巴P. aeruginosa BAA-2114

- Control P. aeruginosa

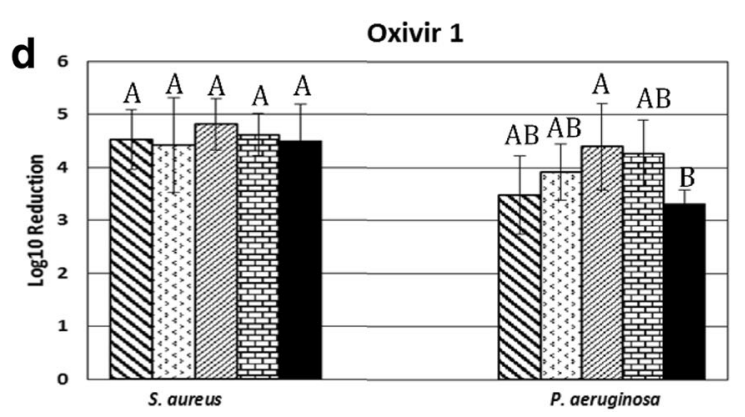

$\triangle$ MRSA BAA-1717

GMRSA BAA-1720

D MRSA BAA-1754

I MRSA BAA-1761

- Control S. aureus

QP. aeruginosa BAA-2108

๒P. aeruginosa BAA-2112

QP. aeruginosa BAA-2113

GP. aeruginosa BAA-2114

- Control P. aeruginosa

Fig. $1 \log _{10}$ reduction values of each bacterial strain for a given disinfectant used at label conditions. Letters above bars indicate statistical grouping and significant differences among strains. a: Bactericidal efficacy of Virex Tb (Quat-based) against various MRSA and P. aeruginosa strains at label conditions (three-minute contact time). b: Bactericidal efficacy of Avert (Chlorine-based) against various MRSA and P. aeruginosa strains at bactericidal label conditions (one minute contact time). c: Bactericidal efficacy of Avert (Chlorine-based) against various MRSA and P. aeruginosa strains at C. difficile sporicidal label conditions (four-minute contact time). d: Bactericidal efficacy of Oxivir 1 (AHP-based) against various MRSA and P. aeruginosa strains at label conditions (one minute contact time)

and $P$. aeruginosa ATCC BAA-2114 $\left(\mathrm{P}_{\mathrm{adj}}=0.0257\right)$ under varying disinfectant concentrations (Fig. 2D).

Disinfectant concentration had a significant effect on the efficacy of Oxivir $1(P=0.0027)$. There was no significant difference in disinfectant efficacy with varying disinfectant concentrations among MRSA strains (Fig. 2E). Oxivir 1 was significantly more effective against $P$. aeruginosa ATCC BAA-2112 (GLMM with Holm-Tukey Correction; $\left.\mathrm{P}_{\mathrm{adj}}=0.0105\right), P$. aeruginosa ATCC BAA$2113\left(\mathrm{P}_{\mathrm{adj}}<0.0001\right), P$. aeruginosa ATCC BAA-2114 $\left(\mathrm{P}_{\mathrm{adj}}=0.0051\right)$ than the control strain at varying disinfectant concentrations (Fig. 2F). Oxivir 1 was significantly less effective against $P$. aeruginosa ATCC BAA$2108\left(\mathrm{P}_{\mathrm{adj}}<0.0001\right)$ than $P$. aeruginosa ATCC BAA- 

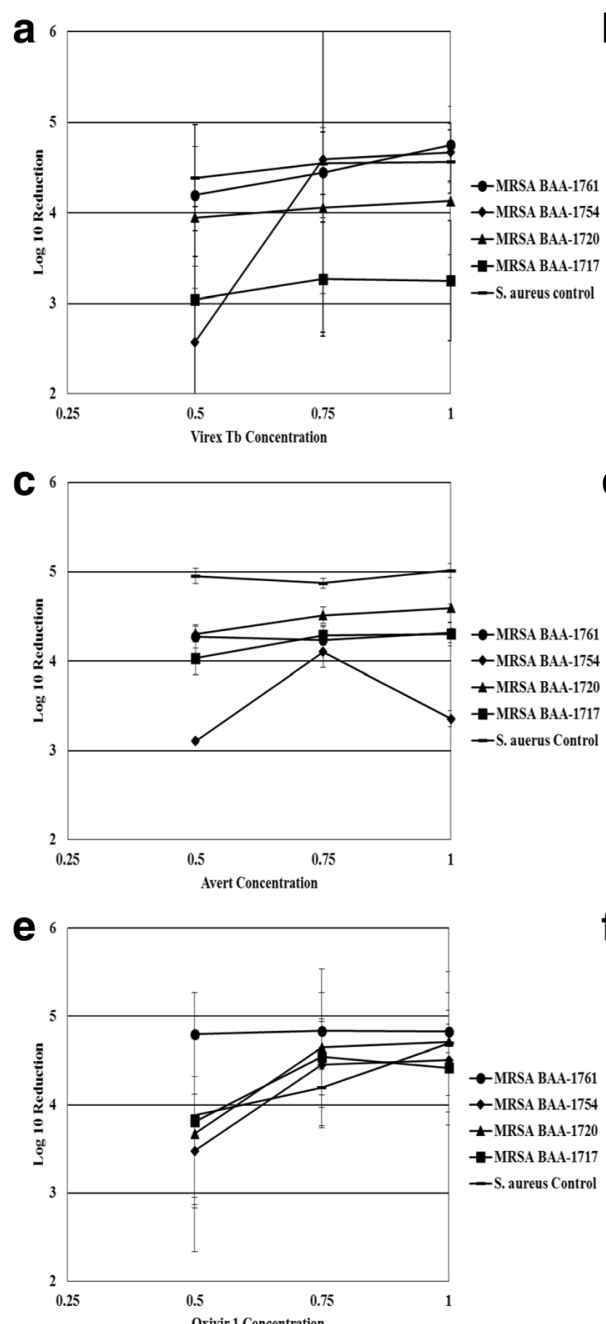
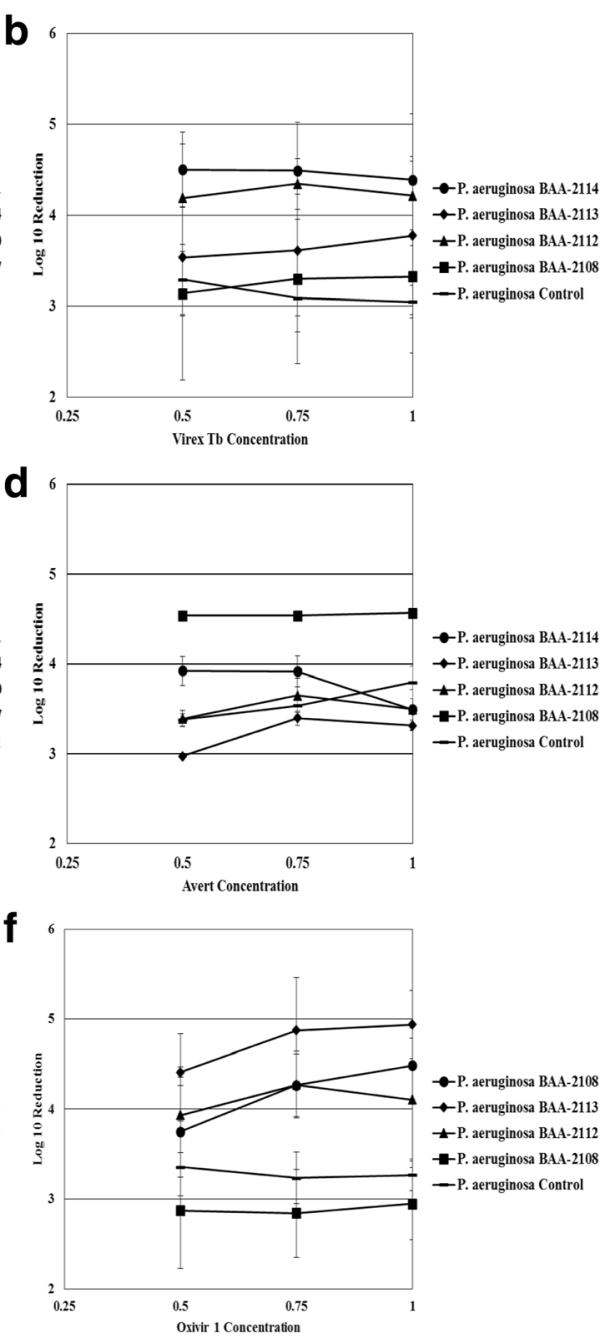

Fig. 2 Effect of varying disinfectant concentration on the bactericidal efficacy of three disinfectants at label concentration. a: Bactericidal efficacy of Virex Tb (Quat-based) against various MRSA strains. b: Bactericidal efficacy of Virex Tb (Quat-based) against various $P$. aeruginosa strains. c: Bactericidal efficacy of Avert (Chlorine-based) against various MRSA strains. $\mathbf{d}$ : Bactericidal efficacy of Avert (Chlorine-based) against various $P$. aeruginosa strains. e: Bactericidal efficacy of Oxivir 1 (AHP-based) against various MRSA strains. Panel F: Bactericidal efficacy of Oxivir 1 (AHP-based) against various $P$. aeruginosa strains

2112, BAA-2113, and BAA-2114 at varying disinfectant concentrations (Fig. 2F).

\section{Reduced disinfectant contact times have varied effects on bactericidal efficacy among strains}

Disinfectant contact time had an overall significant effect on the efficacy of Virex Tb (GLMM; $P<0.0001$ ). The interaction between strain and disinfectant contact time was also significant $(\mathrm{P}<0.0001)$. Virex $\mathrm{Tb}$ was significantly more effective against the control $S$. aureus strain than MRSA ATCC BAA-1717 (GLMM with HolmTukey Correction; $\left.\mathrm{P}_{\mathrm{adj}}<0.0001\right)$, MRSA ATCC BAA$1720\left(\mathrm{P}_{\mathrm{adj}}=0.0007\right)$, and MRSA ATCC BAA-1754 $\left(\mathrm{P}_{\mathrm{adj}}=0.0372\right)$ at varying disinfectant contact times (Fig. 3A). The disinfectant was also more effective against
MRSA ATCC BAA-1761 than both MRSA ATCC BAA1717 and BAA-1754 $(\mathrm{P}<0.0001)$ (Figs. 3A). Virex $\mathrm{Tb}$ was significantly more effective against $P$. aeruginosa ATCC BAA-2114 than P. aeruginosa ATCC BAA-2112 $\left(\mathrm{P}_{\mathrm{adj}}=0.0001\right), P$. aeruginosa ATCC BAA-2113 $\left(\mathrm{P}_{\mathrm{adj}}=0\right.$. $0155)$, and the control strain $\left(\mathrm{P}_{\mathrm{adj}}<0.0001\right)$, at varying disinfectant contact times (Fig. 3B).

Avert was significantly more effective against MRSA ATCC BAA-1717 $\left(\mathrm{P}_{\mathrm{adj}}=0.0215\right)$ and MRSA ATCC BAA-1720 $\left(\mathrm{P}_{\mathrm{adj}}=0.0035\right)$ than MRSA ATCC BAA-1754 at varying disinfectant contact times (Fig. 3C). Avert was significantly more effective against $P$. aeruginosa ATCC BAA-2108 than the other four $P$. aeruginosa ATCC strains (GLMM with Holm-Tukey Correction; all $\mathrm{P}_{\text {adj }}<$ 0.0001) (Fig. 3D). 

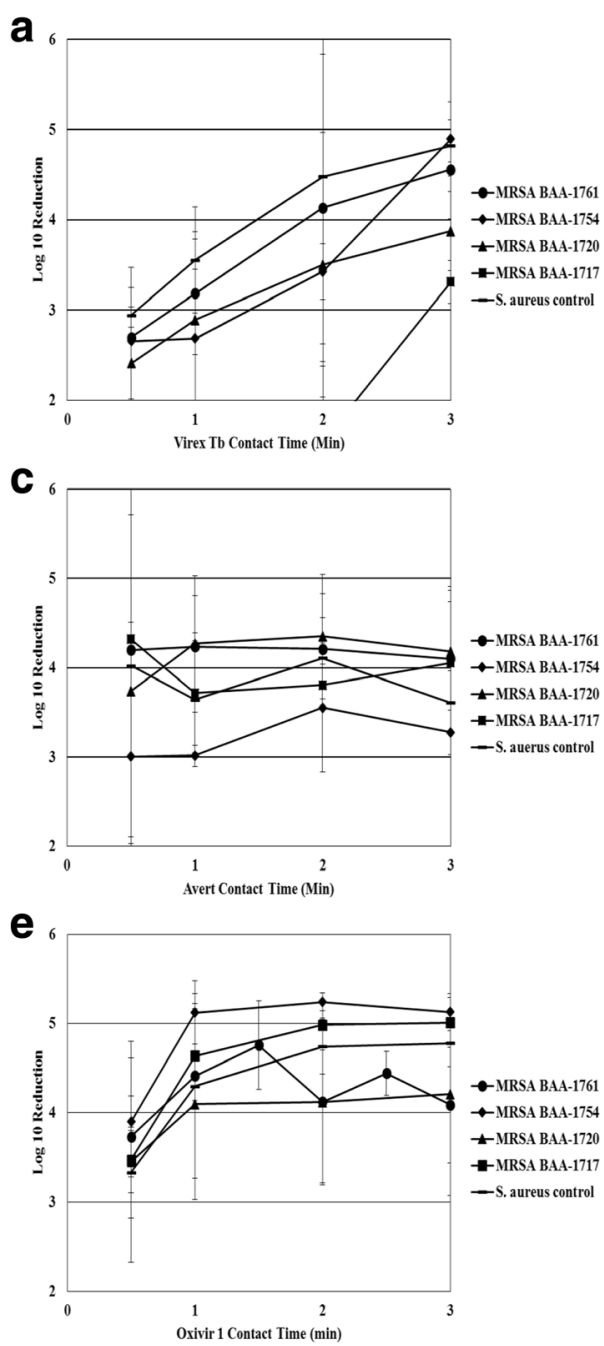
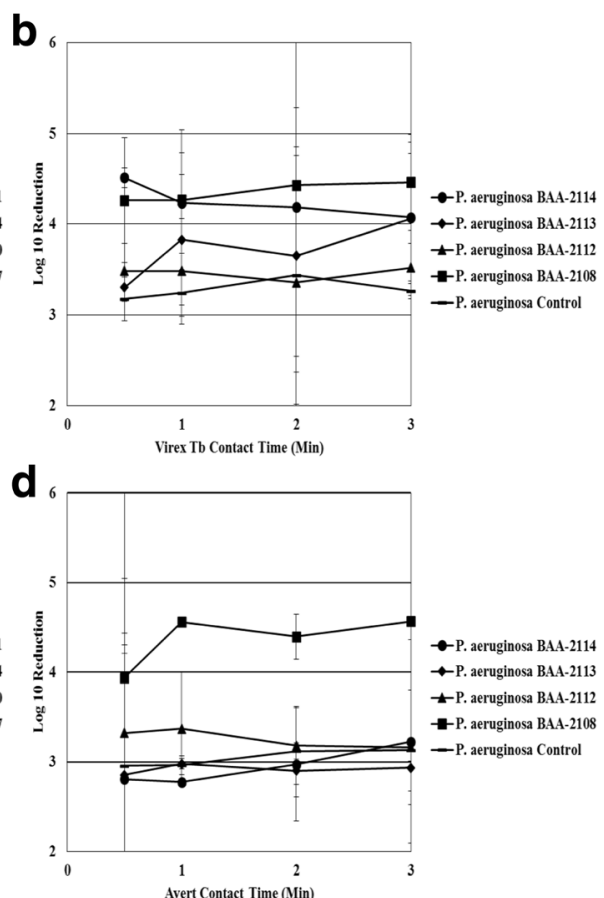

f

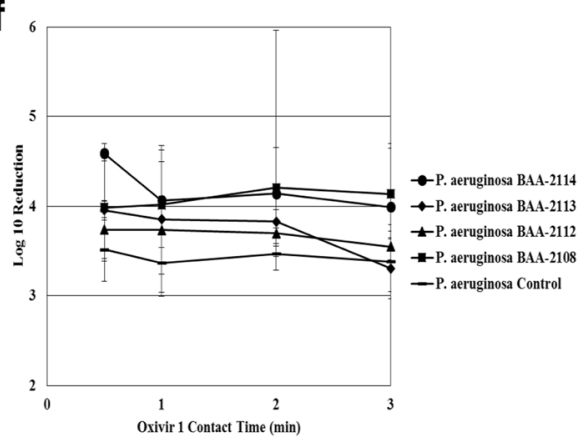

Fig. 3 Effect of varying disinfectant contact time on bactericidal efficacy of three disinfectants at label concentration. a: Bactericidal efficacy of Virex Tb (Quat-based) against various MRSA strains. b: Bactericidal efficacy of Virex Tb (Quat-based) against various $P$. aeruginosa strains. c: Bactericidal efficacy of Avert (Chlorine-based) against various MRSA strains. d: Bactericidal efficacy of Avert (Chlorine-based) against various $P$. aeruginosa strains. e: Bactericidal efficacy of Oxivir 1 (AHP-based) against various MRSA strains. Panel F: Bactericidal efficacy of Oxivir 1 (AHP-based) against various $P$. aeruginosa strains

Overall, disinfectant contact time (GLMM; $P=0.0328$ ) had a significant effect on the efficacy of Oxivir 1. Oxivir 1 was significantly more effective against MRSA ATCC BAA-1754 than MRSA ATCC BAA-1720 ( $\left.\mathrm{P}_{\text {adj }}=0.0099\right)$ and BAA-1761 $\left(\mathrm{P}_{\mathrm{adj}}=0.0008\right)$ (Fig. 3E). Oxivir 1 was significantly more effective against $P$. aeruginosa ATCC BAA-2108 $\left(\mathrm{P}_{\mathrm{adj}}=0.0081\right)$ and $P$. aeruginosa ATCC BAA-2114 $\left(\mathrm{P}_{\mathrm{adj}}=0.0015\right)$ than the control strain at varying disinfectant contact times (Fig. 3F).

\section{Discussion}

In this study, we tested three disinfectants under label and off-label use condition on strains with varying antibiotic resistance profiles using EPA method MB-25-02 [7]. Using this quantitative EPA method, we found significant, quantifiable differences in disinfectant efficacy among strains of $S$. aureus and $P$. aeruginosa at label and off-label use conditions and that these differences varied by disinfectant.

\section{There are significant differences in disinfectant efficacy} among strains tested under label-use conditions

We found significant differences among strains at disinfectant label use conditions; the results varied based on disinfectant. For example, Virex Tb (quat-based) was significantly less effective against MRSA ATCC BAA-1720 yet Avert (chlorine-based) was significantly more effective at sporicidal conditions against the strain. Differences among strains were observed for all disinfectants at label-use conditions. Current EPA testing methods to 
register a healthcare disinfectant (for use on hard nonporous surfaces) requires testing against the two control strains used in this study [11]; it does not evaluate different strains. One of the specific testing methods that can be used for registering disinfectants is AOAC UseDilution method [12]. Positive and negative results are determined through a visual inspection for the presence or absence of turbidity (indicating microbial growth). The AOAC Use-Dilution method is qualitative, whereas the method used in this study (MB 25-02) is quantitative. Our data suggest that further research is warranted to determine if the disinfectant efficacy testing for EPA registration should be re-evaluated to include multiple strains.

\section{Efficacy of reduced concentration and contact time is strain dependent}

Overall, our results showed that disinfectant efficacy varied by strain under off-label conditions. Our data showed that off-label use of a disinfectant product does lead to reduced efficacy. Per United States federal law regarding EPA-registered products, all applicable label instructions must be followed for proper disinfectant use and to achieve full efficacy [13]. A review by Schabrun and Chipchase in 2006 noted that "equipment used in the non-critical setting is less likely to have standard cleaning protocols than equipment used in the critical setting" [14]. A study by Davis looked at blood pressure cuffs as a potential source of cross-contamination in hospitals [15]. This study concluded that that these non-critical medical devices needed more vigilant disinfection procedures and called into question if the time-constrained emergency nurses were best suited for the disinfection role [15]. Furthermore, the CDC's Guidelines for Disinfection and Sterilization in Healthcare Facilities notes numerous factors that may influence a disinfectant's contact time or concentration, and therefore efficacy [13]. Using disinfectants to clean complex medical devices can be challenging. It can be difficult to expose the internal channels of a medical device to the disinfectant for the label contact time, especially as internal air pockets will interfere with this process [13]. In this study, we used disinfectants at ready-to-use concentrations. Concentrated products are common and are typically diluted with water; water hardness can reduce disinfection efficacy. Efficacy can be lowered by the formation of insoluble precipitates due to the presence of divalent cations in hard water [13]. Neither the AOAC Use-Dilution Testing method or the EPA method we used in this study take this real-world problem into account. Both methods use specially prepared water that won't interfere with the disinfectant efficacy testing $[9,12]$.

Although our study highlighted the importance of disinfectant contact time and concentration to achieve efficacy, it is still not well-defined what level of efficacy is needed for a healthcare environment to be considered hygienic. EPA Standard Operating Procedures are very specific on the soil level, surface type, and bacterial strains to be used when doing efficacy testing. This makes it difficult to translate efficacy from lab testing to actual environmental disinfection. This study was limited to ten strains as well, warranting more work to be done.

\section{Conclusion}

In this study, we found differences in disinfectant efficacy amongst strains at label and off-label conditions. Further, we found that concentration and contact time significantly affect disinfectant efficacy of three disinfectants in different ways. The consequences of off-label use of disinfectants is demonstrated in this study. This study underscores the variability of disinfectant efficacy within a bacterial genus. Our data suggests additional strains and additional test methods should be investigated to better understand inter-strain variability.

\section{Abbreviations}

AHP: Accelerated Hydrogen Peroxide; EPA: Environmental Protection Agency; MDR: Multi-Drug Resistant; MRSA: Methicillin Resistant Staphylococcus aureus; PBS: Phosphate Buffered Saline; Quat: Quaternary Ammonium Compounds

\section{Acknowledgements}

We thank Jack Burnett and Sophie Wu for supporting elements of this work.

\section{Funding}

This work was supported by Diversey Inc., Charlotte, NC, USA.

Availability of data and materials

All data generated or analysed during this study are included in this published article [and its supplementary information files].

\section{Authors' contributions \\ AW performed the disinfectant efficacy testing, analysed and interpreted the data generated, and wrote the manuscript. PT provided testing materials, industry experience, and was a contributor in writing and editing the manuscript. CL assisted AW with performing disinfectant efficacy testing and was a contributor in writing and editing the manuscript. $\mathrm{HO}$ served as the principle investigator for the study and was a contributor in writing and editing the manuscript. All authors read and approved the final manuscript.}

Ethics approval and consent to participate Not applicable.

\section{Consent for publication}

Not applicable.

\section{Competing interests}

PT reports grants from Diversey Inc., during the conduct of the study; personal fees from Diversey Inc., outside the submitted work. HO, AW, and $\mathrm{CL}$ all report grants from Diversey Inc., during the conduct of the study.

\section{Publisher's Note}

Springer Nature remains neutral with regard to jurisdictional claims in published maps and institutional affiliations.

\section{Author details}

${ }^{1}$ Department of Food Science, Purdue University, 745 Agriculture Mall Drive, West Lafayette, IN 47907, USA. ²Diversey Inc., Charlotte, NC 28273, USA. 
Received: 6 December 2017 Accepted: 21 March 2018

\section{Published online: 03 April 2018}

\section{References}

1. Magill SS, Edwards JR, Bamberg W, Beldavs ZG, Dumyati G, Kainer MA, et al. Multistate point-prevalence survey of health care-associated infections. N Engl J Med. 2014;370:1198-208.

2. Centers for Disease Control. ABCs report: methicillin- resistant Staphylococcus aureus, https://www.cdc.gov/abcs/reports-findings/ survreports/mrsa14.html; 2014 [accessed 5 May 2017].

3. Driscoll JA, Brody SL, Kollef MH. The epidemiology, pathogenesis and treatment of Pseudomonas aeruginosa infections. Drugs. 2007;67:351-68.

4. Bhalla A, Pultz NJ, Gries DM, Ray AJ, Eckstein EC, Aron DC, et al. Acquisition of nosocomial pathogens on hands after contact with environmental surfaces near hospitalized patients. Infect Control Hosp Epidemiol. 2004;25:164-7.

5. Sexton JD, Wilson AM, Sassi HP, Reynolds KA. Tracking and controlling soft surface contamination in health care settings. Am J Infect Control. 2018;46:39-43.

6. Wendt C, Wiesenthal B, Dietz E, Ruden H. Survival of vacomycin-resistant and vancomycin-susceptible enterococci on dry surfaces. J Clin Microbiol. 1998;36:3734-6.

7. Kramer A, Schwebke I, Kampf G. How long do nosocomial pathogens persist on inanimate surfaces? A systematic review. BMC Infect Dis. 2006;6:130.

8. Quinn MM, Henneberger PK, Braun B, Delclos GL, Fagan K, Haung V, et al. Cleaning and disinfecting environmental surfaces in health care: toward an integrated framework for infection and occupational illness prevention. Am J Infect Control. 2015;43:424-34.

9. Environmental Protection Agency. Antimicrobial testing methods \& procedures: MB-25-02: OECD quantitative method for evaluating bactericidal activity of microbicides used on hard, non-porous surfaces, https://www. epa.gov/pesticide-analytical-methods/antimicrobial-testing-methodsprocedures-mb-25-04; 2013 [accessed 1 September 2016].

10. Hong $Y$, Teska PJ, Oliver HF. Effects of contact time and concentration on bactericidal efficacy of 3 disinfectants on hard nonporous surfaces. Am J Infect Control. 2017; https://doi.org/10.1016/j.ajic.2017.04.015.

11. Environmental Protection Agency. OSCPP 810.2200: Disinfectants for use on hard surfaces-efficacy data recommendations, https://www. regulations.gov/document?D=EPA-HQ-OPPT-2009-0150-0002; 2012 [accessed 24 October 2017].

12. Environmental Protection Agency. Antimicrobial testing methods \& procedures: MB-05-14: AOAC use dilution method for testing disinfectants, https://www.epa.gov/sites/production/files/2016-08/documents/mb-05-14. pdf; 2016 [accessed 15 May 2017].

13. Rutala WA, Weber DJ, and the HICPAC. Guideline for disinfection and sterilization in healthcare facilities, 2008.

14. Schabrun S, Chipchase L. Healthcare equipment as a source of nosocomial infection: a systematic review. J Hosp Infect. 2006;63(3):239-45.

15. Davis C. Blood pressure cuffs and pulse oximeter sensors: a potential source of cross-contamination. Aust Emerg Nursing J. 2009;12(3):104-9.

\section{Submit your next manuscript to BioMed Central and we will help you at every step:}

- We accept pre-submission inquiries

- Our selector tool helps you to find the most relevant journal

- We provide round the clock customer support

- Convenient online submission

- Thorough peer review

- Inclusion in PubMed and all major indexing services

- Maximum visibility for your research

Submit your manuscript at www.biomedcentral.com/submit
Biomed Central 